\title{
Distance Learning in Philippine Business Programs: An Action Research for The Delivery of Quality Education Towards Sustainable Community Development
}

\author{
Eunice Mareth Querol Areola ${ }^{1 *}$, Joan Camille P Ilagan², \\ Irvin Recto Perono ${ }^{3}$ \\ ${ }^{123}$ UST Angelicum College \\ Author E-mail: eunice.areola@ustangelicum.edu.ph
}

\begin{abstract}
A B S T R A C T
Education is one of the hardest hit sectors of the ongoing global health crisis. Elsewhere, educators continue to grapple with their new reality of balancing content, context and form in order to efficiently deliver online the critical teaching and learning in the business programs. A much-needed clarity for the new direction of education is needed by all academic stakeholders. While governments emphasize a new normal for teaching and learning, every student and educator is left with multiple unanswered questions: how does the virtual community expect to learn? Is it enough to know the best practice of a different country context, or should there be local practices that also deserve to be repeated and amplified? Is the local ICT infrastructure sufficient? Are educators equipped with both technical and soft skills? Are students prepared to learn virtually? Do academic institutions have the resources to implement large-scale virtual learning? The adaption for distance learning by the Business programs becomes the center of this action research.
\end{abstract}

Key word: Distance Education, Online Learning, Business Programs, New Pedagogy.

Copyright $(2021$ Authors. This is an open access article distributed under the Creative Commons Attribution License, which permits unrestricted use, distribution, and reproduction in any medium, provided the original work is properly cited.

\section{INTRODUCTION}

Distance education, otherwise known as online education, has received some attention from the Philippine market. With the wide adaptation of the Massive Open Online Courses (MOOCs), many have turned their attention to online learning as a means of coping with the ever-changing environment that has to do with the use of technology, particularly the internet. In relation to this, a significant move to further enhance the Philippine population with the legislation of open distance learning in higher education. This emphasizes all the efforts towards an inclusive education that is recognized in the country, through formal education that is accepted in the workforce.

"MOOCs can reduce the cost of education since these courses are open, free of charge, affordable, and self-paced. You can also earn a certificate by taking MOOCs," according to Marito Garcia (n.d.), former World Bank Lead Economist. With the 
advent of MOOCs, online education in higher education institutions (HEI's) are being reviewed to gain recognition as course credit equivalence (De Dios, 2015).

\section{Issues and Problem Statements}

The Distance Education Rationale in the Philippines On December 9, 2014, the Republic Act 10650 (RA 10650) was signed by then President Benigno Aquino III, which sought to expand access to educational services by institutionalizing open distance learning in tertiary education. This Act is otherwise known as the "Open Distance Learning Act". The Technical Education and Skills Development Authority (TESDA), a Filipino government body, was tasked to assist in the implementation. It offers Massive Open Online Courses and hybrid courses which are free for working Filipinos.

In the initial stages of TESDA's online learning program back in 2011, there were only 100 users according to its Executive Director, Maria Susan P. Dela Rama. The number of online learning users rose to 850,000 in 2016 (Schmitt, 2016), with the integration of RA 10650 and TESDA's continuing efforts.

Adding to the optimism of the usage of MOOCs, Garrido, and Koepke (2015) found that the completion rate in the Philippines is at $41 \%$; where $50 \%$ of those who complete have already attained a college degree or above. They said, "They were doing so to do their jobs better. They felt there were skills they could obtain through MOOCs to do their job better- not necessarily to get a better job within the company or have a promotion."

\section{Distance Education Models in the Philippines}

The adaptation of an online learning model in Philippine academia, however, is faced with challenges in the respective higher education institutions (HEIs). Fifteen (15) HEI's are implementing fully integrated online learning for a course or a complete program. Six (6) of these HEIs are identified as private institutions; nine (9) are state universities funded by the national government. Of the 15 institutions identified, only 3 institutions provide programs for the Bachelor of Science in Business Administration. Specifically, these institutions are Pangasinan State University, Cap College Foundation, and New Era University. For the Master of Business Administration program, there are only 2 institutions identified namely New Era University and Holy Angel University (Courses.com.ph, 2018).

With the above-mentioned status, there is only a limited selection of fully online modalities in higher education institutions, specifically catering to the business discipline. The Asian Development Bank (2017) states, however, that there is a growing number of e-learning and blended learning users. At the time of writing there is no published number of higher education institutions that offer blended learning in their programs.

The overall teaching design in business education requires a turn to active problem-based learning. It generally challenges the instructors in the online environment to develop a curriculum that emphasizes behavioral learning, on top of the fundamental content. The design thinking projects can help the students in the online environment to build their confidence in solving complex problems. Students were asked about the types of challenges faced. Four phases of the teaching design thinking were concluded, namely:

1. Coping with ambiguity, intense engagement in generating ideas, and the repetitive process of diverging and converging that accompanies;

2. Design thinking;

3. Working with human-centered aspects of observing and attending to the needs of users and clients;

4. Learning and using specific tools and methods, such as developing character profiles, journey maps, and prototypes; and

5. Developing interpersonal skills (Glen, Sucio, Baugh \& Anson, 2015).

As far as teaching presence, it was observed in the 
MBA programs in the study of Wisneski, Ozogul, and Bichelmeyer (2015), that teaching presence in the online environment requires instructors to tailor classroom practices for online teaching. Instructors should be able to establish a communication process that goes beyond just presenting course materials, but should lead to dialogues and conversations. Instructors should also communicate the assignments and the course structure, in order to build the perception of the students to the instructor's teaching presence. Lastly, encouragement, affirmation, or validation is important for the instructor to build the teaching presence.

Features of Sub-systems Operating in the DE Programs

Based on the findings of Sanford (2017), the GPA of a student may be impacted whenever course sectioning takes place. It was observed that students with low GPA's tend to learn poorly in online learning courses. He, therefore, suggests that GPA-related policies be enforced whenever assigning students in online course sections. This is observed in the behavior of 269 students of Association to Advance Collegiate Schools of Business (AACSB) - accredited undergraduate business programs. This brings about suggestions that student readiness is measured in terms of profile such as age, personality and GPA (Kulchitsky, Wright, \& Ricker, 2009; Parnell \& Carraher, 2003). It was further suggested that GPA can be used as a basis for limiting access to online course sections to improve student learning and student retention (Hachey, Wladis \& Conway, 2013).

Another suggestion is for the institutions to design the online environment with a resemblance to a face-to-face modality. It is given that there have been developments in terms of state-of-theart online course platforms, professor training, and course content updates however, this is not true for all institutions. Improving the studentprofessor and student-student interaction may improve the student learning experience (Watson \& Sutton, 2012). Activities, such as live interactive television, reduce the transactional distance between the professor and the students (Lemak, Reed, Montgomery, \& Shung Jae, 2005).

Pedagogical Issues and Challenges Encountered in Distance Education of Business Programs

Online learning has a trend that is constantly being developed through the internet. It is being used by different educational providers, most especially those in higher education. As relevant as it is, there are identified barriers to this kind of learning, particularly where interaction is seen as an important medium in learning. This barrier to learning can be divided into four categories: individual, behavioral, course design, and administrative factors (Purarjomandlangrudi, Chen \& Nguyen, 2016). But beyond these four learning barriers, we acknowledge that has allowed the growth of this kind of education for a vast audience. Some of whom are not capable of attending higher education (Hendricker, Saeki \& Viola, 2017). Keengwe, Adjei-boateng \& Deteeyont, as cited by Cameron et al. in 2009, mentioned that an online collaborative learning environment functions to connect the students to interact amongst each other. It requires the instructors to create interactive environments which harness the benefits of sharing knowledge, opportunities to explore issues, increase inspiration and motivation, interact with other individuals, reduce feelings of isolation and increase access to shared resources (Keengwe, Adjei-boateng \& Deteeyont, as cited by Petropouloua et al. 2010).

Moore (2014) argues, however, that a continued instructor presence may likewise result in a negative effect on learner retention. This being an effect of non-directed instructor communication in online courses and concluded as not helpful to online students. Instructor comments in the form of general messages such as praising, reinforcing, and or correcting all students. Students who paid more attention readily got the message and passed their courses. Those who did not pay attention tend to not get the message and therefore, failed their courses. This becomes imperative that online instructors use a more direct form of communication with the 
students.

In an online learning environment, interaction, social bond, and emotional intelligence play an important role in emotional and social learning. However, there have been no studies that investigate the role of emotional intelligence and the interactions among students. The transactional distance between the students and instructors is lessened with greater positive interactions. Perceiving emotions through online interactions, such as in the case of students with higher emotional intelligence, lessen the transactional distance with their peers (Han \& Johnson, 2012). According to Wei, Chen \& Kinshuk (2012), attempt to develop both the user interface coupled with the appropriate social cues in order to attain a level of perceived presence in online learning environments. Through relevant guidance, encouragement, grouping, and rewards strategies, instructors are encouraged to improve interaction among the students.

\section{METHODOLOGY}

The methodology includes observations of online education and student learning experience. Local business schools still adopt a more traditional way, given that there is no reported number of those offering a hybrid modality for both the undergraduate and graduate programs. As observed in the business programs, based on the literature reviewed, an important element is the system of enrollment of students in the online courses. Based on GPA and other assessment factors, barring a student from enrolling becomes beneficial to his/her learning experience. Another method is done by observing professors' role in online education. As in any institution, professors are a vital factor in teaching courses. Technology and content also play a crucial element, as this eases the transactional distance in the online learning environment. The method to address the existence of the subsystem in Philippine universities is presented by Moore and Kearsley (2011) with the variables shown in boxes (Figure 1).

This design suggests that in the distance education system, technology independence is first and foremost ensured. Technology plays an important role in the system. It encompasses how the online courses are delivered in terms of device compatibility, bandwidth accommodation, minimum hardware requirements, and required software. Technological infrastructure that is more dependent than independent may collapse the overall structure of the system. Based on Moore and Kearsley's design, learning, faculty, and course design are present. However, based on the provided literature, the registrar should perform equal functional importance to the student experience given that admitting students who are not ready for online learning may fail (Sanford, 2017). Likewise, students who have already proven that online learning may be detrimental to their journey should be advised to take on a different modal approach that could better suit their learning preferences. Management functions in the distance education environment in the Philippines should only encompass all subsystems in a way that all adheres to the policies and procedures of the institution.

When it comes to actual learning, the study of Shahabadi and Uplane (2015) poses an interesting take on which type of delivery fits

Figure 1. Proposed Distance Education Model for Business Programs in the Philippines

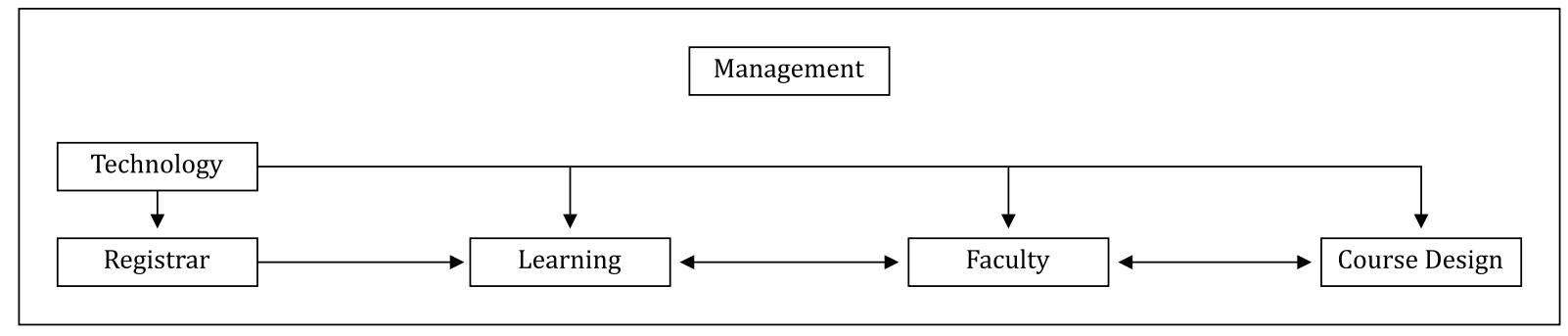


best synchronous or asynchronous learning. Operationally, there are four learning styles in the study namely diverging, assimilating, converging, and accommodating. Diverging style entails feeling and watching. Assimilating entails thinking and watching. Converging entails thinking and doing. Accommodating entails feeling and doing. The variables are based on Kolb's learning style theory. It was concluded that the most preferred learning style in asynchronous learning is converging and assimilating, with a common theme in thinking, otherwise termed as abstract conceptualization. It is noted that in this learning style, abstract concepts are geared towards scientific approaches rather than artistic approaches. Synchronous learners were found to prefer assimilating and diverging, with a common theme in watching, otherwise termed as reflective observation. It is suggested that synchronous tutorial concepts, chat tools, video conferencing and individualized learning projects be the types of activities for learning.

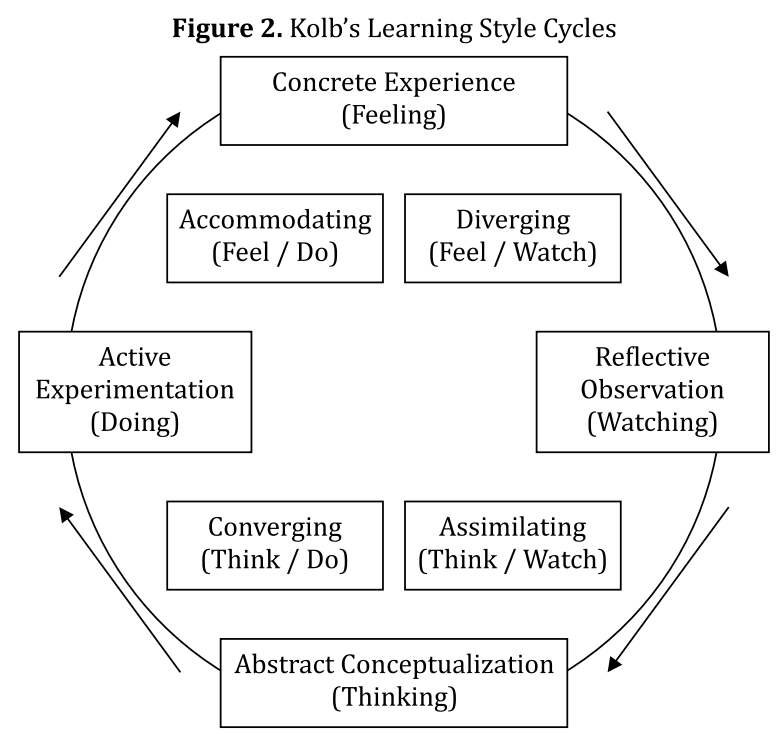

The methodology also includes direct interviews with the informants. Not only through observations, but the study is also done through in-depth interviews to analyze the delivery of quality education towards sustainable community development.

\section{RESULTS AND DISCUSSIONS}

Issues Encountered in Adapting Distance Education

\section{in Philippine Business Schools}

As the Philippines have yet to fully integrate an online experience in higher education institutions, a few people were interviewed to determine their points of view concerning their experiences in an online environment in a business program. The institutions and the names have been masked to protect their interests.

"We were using our 'learning management system' (LMS) for quizzes, seat works, and homework. There were a lot of class suspensions during my stay in the university and we were using NEO just to make up for the lost time. In truth, some students copy and paste the questions in google so they can search for the correct answers." - Marie, undergraduate student, University A.

"Connection issues were mainly the problem among students." - Peter, faculty, University B.

"We were meeting, as a class, online. We read a chapter, then we do the homework. The 'classroom' is actually a chat session. The challenge is when there is a topic to clarify and when there is a question to raise. It is hard to expound on chats. I also don't know who my classmates are when I ask a question. Learning felt like a solo effort. I think that tests conducted online should have a real-time and security feature to it." - Earl, graduate student, University C.

"We are using a free eLearning tool. I noticed that the main problem is connectivity when the students are using the school's Wi-Fi access. Some students also have a hard time following instructions and they feel shy about asking questions. They find it more comfortable to ask questions during face-to-face contact." - Rose, faculty, University D.

"LMS is used in a blended learning environment. In terms of navigation, there is an orientation given to the students, before their immersion with the online environment. This ensures that there is no navigation issue encountered by the students. The common challenge for students is the Wi-Fi 
connectivity on campus. Sometimes, they also tend to claim that the faculty did not upload the material, even if it is really there. They're lazy to look for them." Jane, faculty, University E.

\section{Where the Philippines Stand in Online Education}

In summary, the majority of challenges encountered in this sample of two universities could be categorized as related to academic honesty, lack of interaction with peers (isolation), lack of motivation, and connectivity issues. MOOCs provided by TESDA do not encounter issues with academic honesty, interaction, and motivation, primarily because it can be attributed to the willingness and acceptance of the online learning model. However, students of HEIs are served with a general adaptation of an online learning environment where its primary function is alternative learning during class suspensions. As demonstrated in the interviews, a fully online environment has a positive outlook on learning and has no general citation of any challenges encountered.

The last general issue is connectivity. It is a general fact that the Philippines experiences a relatively slow, yet expensive cost of Internet service. The Philippines' average download speed is $3.64 \mathrm{Mbps}$, while the global average speed is 23.3Mbps (Marasigan, 2016). This issue cannot be readily solved by any other institution, as discussed in the cited literature. HEIs should otherwise be mindful of this concern in order to maximize the online learning experience.

\section{CONCLUSION AND RECOMMENDATION}

In the interview conducted, challenges faced were related to academic rigor through academic honesty, lack of interaction and motivation through transactional distance, and connectivity issues. Through a good technological infrastructure, not necessarily that of hardware, but of tools that can encourage engagement (interactive), academic rigor (anti-plagiarism and grammar checking), and accommodate these at minimum bandwidth possible, these indeed enhance the overall learning experience in the online space, based on Moore and Kearsly's framework. It is also worth noting that both in synchronous and asynchronous learning, based on Kolb's theory, the idea that students are 'watching' or enhancing the reflective observation skills reinforces the thought that delivery should be interactive in nature.

It cannot be overemphasized that creativity in the creation and transfer of teaching and learning plays a critical role in the success of online academic delivery. While the challenge may be greater for the more technical courses like those that are offered in the business programs, the reality remains that there is no going back to the old ways of teaching and learning. As both the learners and learning facilitators became more aware of the new technology and gamification applications that were made available in recent months, the demand for more relevant, responsive, dynamic, and interactive teaching and learning, albeit virtually will continue to grow.

More importantly, the education of the future, particularly in the business programs should concentrate on content and context, rather than just on form or modality. Delivery of quality education would be more impactful towards sustainable community development when more relevant cases can be explored, and educators could develop their talents in essaying reallife business situations wherein students can simulate strategic actions, practice opportunity creation, become hardwired for risk identification and be proactive at problem mitigation. 


\section{REFERENCES}

Asian Development Bank (2017). Blended Learning and e-Learning are Improving Access to Education. Retrieved from

https://www.adb.org/news/features/blended-learning-and-e-learning-are-improving-accesseducation

Courses.com.ph (n.d.) Schools, colleges and universities in the Philippines that offer online courses. Retrieved from

http://www.courses.com.ph/schools-colleges-and-universities-in-the-philippines-that-offeronline-courses/

De Dios, E. (2015). The Use of MOOCs as a Potential Avenue to Modernize Learning in the Philippines. Philippine Institute for Development Studies. Retrieved from https://dirp3.pids.gov.ph/websitecms/CDN/PUBLICATIONS/pidsdps1553.pdf

Garcia, M. (n.d.). Proceedings from the forum of the Philippine Institute for Development Studies (PIDS). Makati City, Philippines

Garrido, M. \& Koepke, S. (2015). The advancing MOOCs for development initiative. An examination of MOOC usage for professional workforce development outcomes in Colombia, the Philippines, \& South Africa. Retrieved from

https://www.irex.org/sites/default/files/node/resource/examination-mooc-usage-professionalworkforce-development-outcomes.pdf

Glen, R., Suciu, C., Baughn, C.C. \& Anson, R. (2015). Teaching design thinking in business schools. The International Journal of Management Education. 13, 182-192.

Hachey, A. C., Wladis, C.W., \& Conway, K. M. (2013). Balancing retention and access in online courses: Restricting enrollment... Is it worth the cost? Journal of College Student Retention: Research, Theory \& Practice, 15(1), 9e36.

Han, H., \& Johnson, S. D. (2012). Relationship between students' emotional intelligence, social bond, and interactions in online learning. Journal of Educational Technology \& Society, 15(1), 78-n/a. Retrieved from https://search.proquest.com/docview/1287024875?accountid=194676

Hendricker, E., PhD., Saeki, E., PhD., \& Viola, S., PhD. (2017). Trends and perceptions of distance learning in school psychology. Trainers' Forum, 34(2), 36-68. Retrieved from https://search.proquest.com/ docview $/ 2032393453$ ?accountid $=194676$

Keengwe, J., Adjei-boateng, E., \& Diteeyont, W. (2013). Facilitating active social presence and meaningful interactions in online learning. Education and Information Technologies, 18(4), 597-607. doi:http://dx.doi.org/10.1007/s10639-012-9197-9

Kolb, D., \& Kolb, A. Y. (2005). The Kolb Learning Style Inventory-Version 3.1, 2005 Technical Specifi cations. Boston: MA:Hay Resources Direct.

Kulchitsky, J. D., Wright, M., \& Ricker, L. (2009). Assessing the discriminant ability of the MEBIR scale: An on-line versus on-campus application. International Journal of Management Education, 7(3), $69 \mathrm{e} 79$.

Lemak, D. J., Reed, R., Montgomery, J. C., \& Shung Jae, S. (2005). Technology, transactional distance, and instructor effectiveness: An empirical investigation. Academy of Management Learning \& Education, 4(2), 150e159.

Marasigan, L. (2016). PHL's slow but expensive Internet service. Business Mirror. Retrieved from https:// businessmirror.com.ph/2016/10/13/phls-slow-but-expensive-internet-service-4/

Moore, J. (2014). Effects of online interaction and instructor presence on students' satisfaction and success with online undergraduate public relations courses. Journalism \& Mass Communication Educator, 69(3), 271-288. Retrieved from https://search.proquest.com/docview/1559859935?accountid=194676. 
Parnell, J. A., \& Carraher, S. (2003). The Management Education by Internet Readiness (MEBIR) scale: Developing a scale to assess one's propensity for Internet-mediated management education. Journal of Management Education, 27, 431e446.

Purarjomandlangrudi, A., Chen, D., \& Nguyen, A. (2016). Investigating the drivers of student interaction and engagement in online courses: A study of state-of-the-art. Informatics in Education, 15(2), 269-286. doi:http://dx.doi.org/10.15388/infedu.2016.14.

Sanford, D. (2017). Course format and learning: The moderating role of overall academic performance. The International Journal of Management Education. 15, 490-500

Schmitt, J. (2016). The Philippines and other developing countries ramp up online education culture. Retrieved from https://www.forbes.com/sites/schmittjason/2016/08/25/the-philippines-andother-developing-countries-ramp-up-online-education-culture/\#28ccfa6075eb

Shahabadi, M. M. \& Uplane, M. (2015). Synchronous and asynchronous e-learning styles and academic performance of e-learners. Procedia - Social and Behavioral Sciences. 176, 129-138.

Watson, S., \& Sutton, J. M. (2012). An examination of the effectiveness of case method teaching online: Does the technology matter? Journal of Management Education, 36(6), 802e821. http://dx.doi.org/10.1177/1052562912445281.

Wei, C., Chen, N., \& Kinshuk. (2012). A model for social presence in online classrooms. Educational Technology, Research and Development, 60(3), 529-545. doi:http://dx.doi.org/10.1007/s11423012-9234-9

Wisneski, J.E., Ozogul, G., \& Bichelmeyer, B.A. (2015). Does teaching presence transfer between MBA teaching environments? A comparative investigation of instructional design practices associated with teaching presence. Internet and Higher Education. 25, 18-27 